\title{
Thrombosed aneurysm of saphenous vein coronary artery bypass grafting
}

\author{
Rodolfo Mendes Queiroz ${ }^{1 *}$, Rogério Nastri Filho ${ }^{1}$, Marcus Antônio Ferez $^{1,2}$, Mauro José Brandão da Costa ${ }^{1}$, \\ Claudio Benedini Laguna ${ }^{1}$, Marcus Vinicius Nascimento Valentin ${ }^{1}$
}

${ }^{1}$ Radiology and Imaging Diagnosis Department, Documenta - Hospital São Francisco, Ribeirão Preto, SP, Brazil 2Intensive Care Center Department, Hospital São Francisco, Ribeirão Preto, SP, Brazil

\section{SUMMARY}

Study conducted at Documenta Centro Avançado de Diagnóstico por Imagem, Hospital São Francisco, Ribeirão Preto, SP, Brazil

Article received: $11 / 25 / 2016$ Accepted for publication: $12 / 1 / 2016$

*Correspondence: Address: Rua Bernardino de Campos, 980 Ribeirão Preto, SP - Brazil Postal code: 14015-130 rod_queiroz@hotmail.com

We describe the case of a male patient, aged 76 years, referred for cardiac investigation due to retrosternal chest pain and dyspnea. He had a history of acute myocardial infarction and angioplasties in the last 30 years, including a saphenous vein coronary artery bypass grafting (SVCABG). Echocardiogram showed hypoechoic oval formation near the right ventricle, suggesting a pericardial cyst. Computed angiotomography revealed a predominantly fusiform and thrombosed aneurysmal dilation of the SVCABG to the right coronary artery. SVCABG aneurysms are very rare and potentially fatal. They usually appear in the late postoperative period, and patients are often asymptomatic. On radiography, it is frequently presented as enlargement of the mediastinum, with echocardiography, computed tomography and magnetic resonance imaging being very useful for diagnosis. Coronary angiography is the gold standard to detect these cases. Our report illustrates a rare situation arising late from a relatively common surgery. Due to its severity, proper recognition in the routine assessment of patients with a similar history is essential.
\end{abstract}

http://dx.doi.org/10.1590/1806-9282.63.06.488
Keywords: aneurysm, bypass, coronary, saphenous, myocardium.

\section{Case report}

Male patient, 76 years old, underwent complementary investigation through imaging examinations due to complaints of retrosternal chest pain and mild dyspnea several months ago. The patient reported hospitalization and clinical treatment of acute myocardial infarction one month before. The patient had hypertension, dyslipidemia, was a former smoker and had a history of two other acute myocardial infarctions prior to 2010. The patient's history included saphenous vein coronary artery bypass grafting (SVCABG) for about 30 years, two percutaneous transluminal coronary angioplasty procedures, one with stenting to clear the SVCABG, and surgical repair of abdominal aortic aneurysm with endoprosthesis for approximately 4 years. Reports of catheterizations prior to 2015 described new SVCABG occlusion.

A chest radiograph showed only a metallic sternal suture and a small stent near the cardiac silhouette (Figure $1 \mathrm{~A}$ and $\mathrm{B})$.

The echocardiogram showed a hypoechoic, elongated oval image, adjacent to the right cardiac chambers, causing a slight extrinsic compression on diastole (Figure 2A and B), apparently without flow according to color Doppler investigation. The diagnostic possibility of pericardial cyst was raised.

Computed tomography of the thorax showed a large, oval and elongated hypoattenuating (approximately 45 $\mathrm{HU}$ ) mediastinal mass with lobulated contours, located in close contact with the right heart chambers, presenting peripheral parietal calcifications with a maximum caliper of $4.9 \mathrm{~cm}$ and measuring approximately $10.0 \mathrm{~cm}$ in length (Figure 3A-C), not enhanced after the injection of intravenous contrast medium (Figure $3 \mathrm{D}-\mathrm{F}$ ). The mass could be seen from the emergence of the ascending aorta, with the small stent evident in its interior, extending even to the lower cardiac wall. Such findings were compatible with thrombosed SVCABG aneurysm in the right coronary artery.

Due to the high surgical risk, as well as clinical and electrocardiographic stability of the patient, we opted for conservative management and clinical therapy for general support with periodic follow-up. 


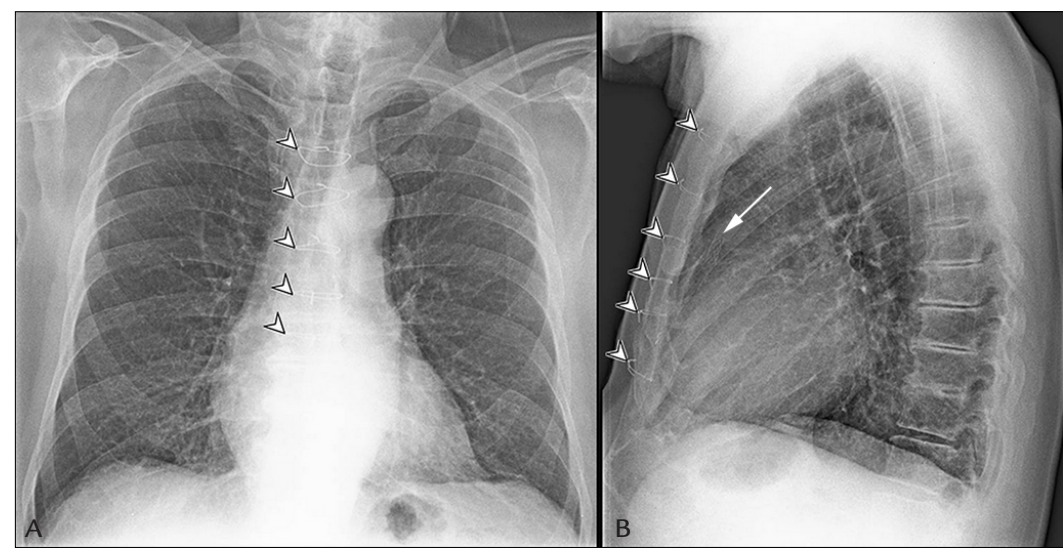

FIGURE 1 Chest X-ray in posteroanterior (A) and profile (B) views, showing mainly the metallic sternotomy (arrow heads) and the small stent along the cardiac silhouette (small arrow).

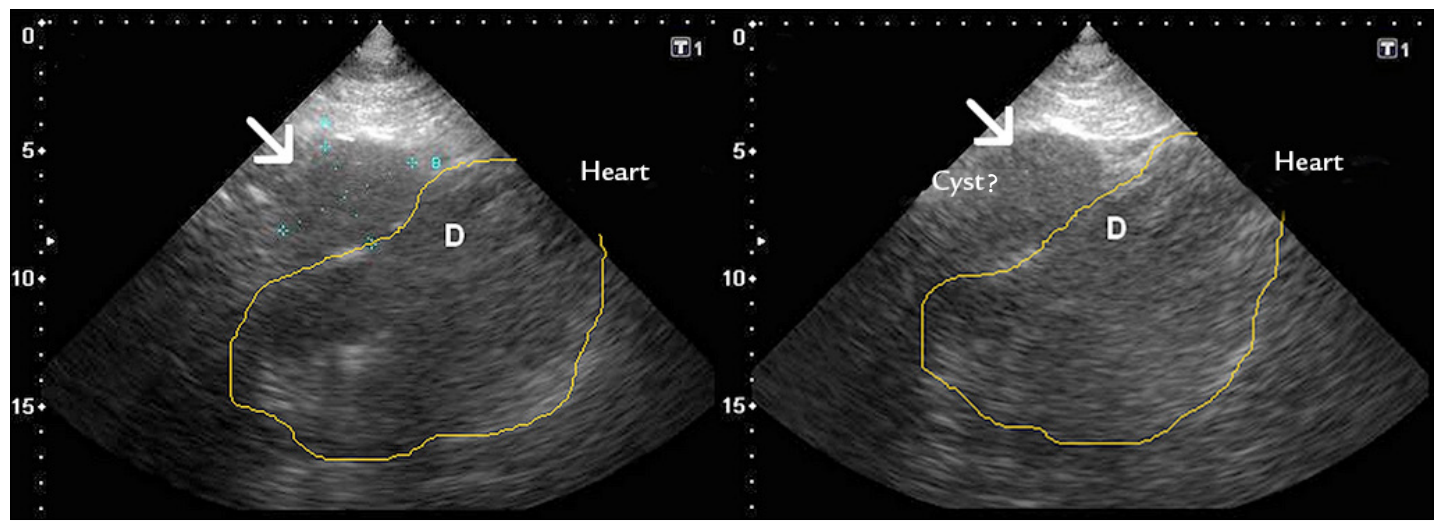

FIGURE 2 A and B. Echocardiogram showing a hypoechoic oval image (thin arrow) adjacent to the right cardiac chambers that causes slight compression in the latter.

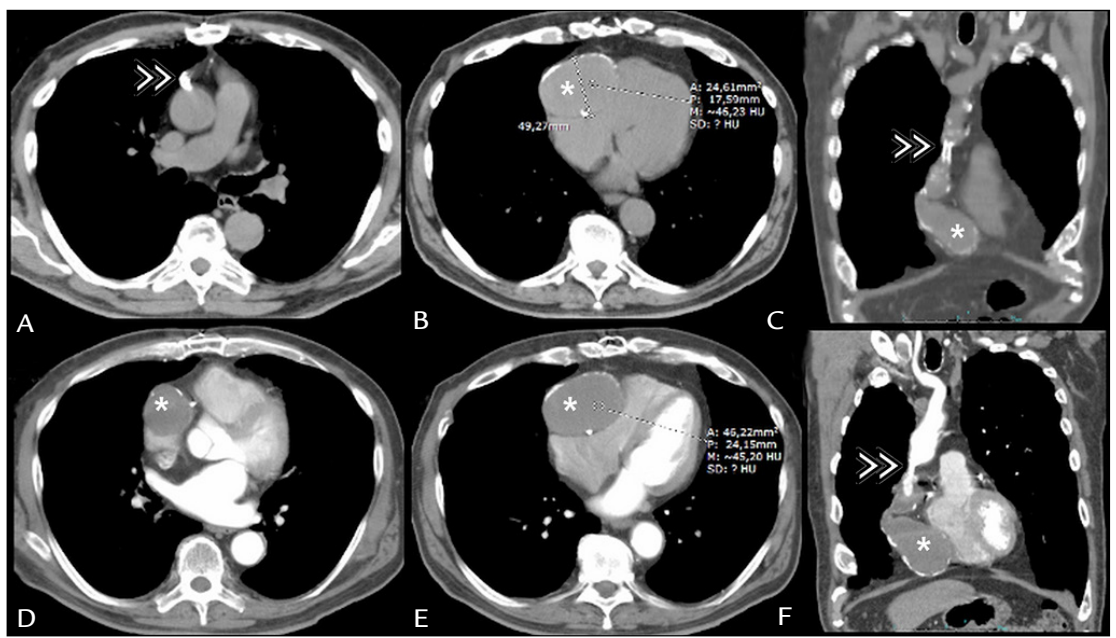

FIGURE 3 Computed tomography of the chest, images acquired before (A, B, C) and after (D, E, F) the administration of intravenous contrast medium, showing aneurysms of aortocoronary saphenous vein bypass grafts to the right coronary artery $\left({ }^{*}\right)$ and the small stent in its implantation surgical ostium (thin double arrowheads). The aneurysm is characterized by a large oval and elongated formation in the middle mediastinum, hypoattenuating, with lobulated contours and in close contact with the right heart chambers. It presents peripheral parietal calcifications, without enhancement after intravenous iodine contrast. 


\section{Discussion}

Aneurysmal formations, also known as "saphenous bridges," are rare in SVCABG. These cases should be differentiated from ectasia, which does not exceed 1.5 times the normal vessel size and is observed in about $14 \%$ of patients 5-7 years after surgery. ${ }^{1-4}$

They can be divided into pseudoaneurysms and true aneurysms. Pseudoaneurysms do not involve all the usual layers of the vascular wall. They occur earlier and usually close to anastomoses, often related to trauma, surgical technique problems, infections and the preparation of the vein. ${ }^{1}$ True aneurysms usually occur later, consisting of true distended walls, often associated with atherosclerosis, hyperlipidemia, endothelium weakness, and smoking. ${ }^{1}$ Aneurysms are commonly diagnosed 10 years after revascularization $(69 \%){ }^{5}$

The incidence of aneurysmal formations in SVCABG varies between 0.07 and $2 \%,{ }^{6,7}$ with the most common being true aneurysms (61-86\%), ${ }^{3,5,7,8}$ The two types of aneurysm predominate in men (76-86\%) between 50-75 years. ${ }^{3,5,7,8}$ Approximately $45-66 \%$ of the patients have symptoms, especially chest pain, angina and dyspnea. ${ }^{5}$

The discovery of aneurysmal formations often occurs incidentally due to mediastinal enlargement identified on chest radiography performed for other reasons. ${ }^{4,69}$ The golden standard of diagnosis is coronary angiography, ${ }^{1}$ but echocardiography, computed tomography and magnetic resonance imaging can also be used. ${ }^{1}$ The latter two evaluate size, permeability and the relationship with neighboring structures. ${ }^{9}$

The most-affected SVCABGs are those directed to the right coronary arteries (38\%) and the left anterior descending artery (25\%). ${ }^{5}$ They can become quite large, ${ }^{4,7}$ with a mean diameter between 6.0 and $7.0 \mathrm{~cm}$, often with internal thrombi or thrombosed (61\%). ${ }^{5}$

Approximately $36 \%$ of cases develop with complications such as rupture with consequent hemothorax and hemopericardium, ${ }^{1,6,9}$ thromboembolism, fistulas, acute myocardial infarction, heart failure and compression of adjacent structures, $1,4-7,9$

Surgical treatment with new revascularization is recommended even in asymptomatic patients, due to the high mortality rate in case of rupture. Conservative therapy such as the use of polytetrafluoroethylene-coated stents, hemodynamic embolization with coils or amplatzer vascular plug is advised in individuals with a very high surgical risk, followed by imaging tests. ${ }^{1-9}$
Our report illustrates a rare situation arising late from a relatively common surgery. Due to its severity, proper recognition in the routine assessment of patients with a similar history is essential.

\section{Resumo}

Aneurisma trombosado de bypass aortocoronariano de veia safena

Descrevemos o caso de paciente do sexo masculino, 76 anos, em avaliação cardiológica em razão de dor torácica retroesternal e dispneia. Antecedente de infartos agudos do miocárdio e angioplastias nos últimos 30 anos, incluindo um bypass aortocoronário de veia safena (BACVS) ou "ponte de safena". Em ecocardiograma, observou-se formação ovalada alongada hipoecoica junto ao ventrículo direito, podendo sugerir um cisto pericárdico. Angiotomografia computadorizada do tórax evidenciou uma dilatação aneurismática predominantemente fusiforme e trombosada de "ponte de safena" para artéria coronária direita. Aneurismas de BACVS são raríssimos e potencialmente fatais. Geralmente, surgem em um período tardio pós-cirúrgico, sendo seus portadores muitas vezes assintomáticos. Na radiografia, frequentemente se apresentam como alargamento do mediastino, sendo a ecocardiografia, a tomografia computadorizada e a ressonância magnética muito úteis no diagnóstico. A angiografia coronariana é o padrão-ouro na detecção. Este relato ilustra uma situação rara decorrente tardiamente de uma cirurgia relativamente comum, e por causa de sua gravidade torna-se essencial o seu reconhecimento na rotina de avaliação de pacientes com antecedentes semelhantes.

Palavras-chave: aneurisma, bypass, coronária, safena, miocárdio.

\section{References}

1. Albuquerque MG, Farran JA, Pereira CAP, Romano ER, Brotto INM, Romano MLP. Giant aneurysm of saphenous vein bypass for right coronary after angioplasty. Arq Bras Cardiol. 2012; 99(2):125-7.

2. Frazier AA, Qureshi F, Read KM, Gilkeson RC, Poston RS, White CS. Coronary artery bypass grafts: assessment with multidetector CT in the early and late postoperative settings. Radiographics. 2005; 25(4):881-96.

3. Kalimi R, Palazzo RS, Graver LM. Giant aneurysm of saphenous vein graft to coronary artery compressing the right atrium. Ann Thorac Surg. 1999; 68(4):1433-7.

4. Memon AQ, Huang RI, Marcus F, Xavier L, Alpert J. Saphenous vein graft aneurysm: case report and review. Cardiol Rev. 2003; 11(1):26-34. 
5. Ramirez FD, Hibbert B, Simard T, Pourdjabbar A, Wilson KR, Hibbert R, et al. Natural history and management of aortocoronary saphenous vein graft aneurysms: a systematic review of published cases. Circulation. 2012; 126(18):2248-56.

6. Fukui T, Suehiro S, Shibata T, Sasaki Y, Minamimura H, Kinoshita H. Aortocoronary saphenous vein graft aneurysm in redo coronary artery bypass grafting: report of a case. Surg Today. 1998; 28(3):321-4

7. Dieter RS, Patel AK, Yandow D, Pacanowski-Jr JP, Bhattacharya A, Gimelli $\mathrm{G}$, et al. Conservative vs. invasive treatment of aortocoronary saphenous vein graft aneurysms: Treatment algorithm based upon a large series. Cardiovasc Surg. 2003; 11(6):507-13.

8. Almanaseer Y, Rosman HS, Kazmouz G, Giraldo AA, Martin J. Severe dilatation of saphenous vein grafts: A late complication of coronary surgery in which the diagnosis is suggested by chest X-ray. Cardiology. 2005; 104(3):150-5

9. Távora FR, Jeudy J, Burke AP. Multiple aneurysms of aortocoronary saphenous vein grafts with fatal rupture. Arq Bras Cardiol. 2007; 88(5):107-10. 